\title{
Processing novel compounds: Evidence for interactive meaning activation of ambiguous nouns
}

\author{
RIET COOLEN, HENK J. VAN JAARSVELD, and ROBERT SCHREUDER \\ University of Nijmegen, Nijmegen, The Netherlands
}

\begin{abstract}
In three experiments, the meaning activation of ambiguous nouns in novel nominal compounds was investigated. Ambiguous nouns were unbalanced homographs occurring as the second members of the compound. Meaningful interpretations of the compounds were based on either the dominant or the subordinate meaning of the ambiguous noun. In Experiment 1, visually presented novel compounds serving as primes were followed at varying intervals by targets associatively related to distinct meanings of the ambiguous noun. In a lexical decision task, facilitation effects were found only for targets related to the meaning that was relevant for the interpretation of the compound. Experiment 2 showed that interactive activation could not be attributed to differences in semantic relatedness between the first members of compounds and targets. Experiment 3 demonstrated equal intralexical relatedness between members for both types of compounds. It is proposed that interactive activation may facilitate the interpretation of the novel compound. Compatible meaning aspects of the nouns may become more strongly activated, and incompatible meaning aspects may not become activated. The selection of meaning aspects relevant for interpretation would thereby be simplified.
\end{abstract}

Novel nominal compounds that consist of simple juxtapositions of two or more nouns, examples of which can be found in English and Dutch, do not provide explicit cues on how to integrate the nouns into some meaningful interpretation of the compound. ${ }^{1}$ Relational ambiguity arises because of the absence of such cues (Wisniewski $\&$ Gentner, 1991). Constituent nouns of the same compound may be related in different ways, resulting in quite different interpretations of the novel compound (BoaseBeier, 1987; Downing, 1977; Gleitman \& Gleitman, 1970; Lees, 1970; Levi, 1978). For example, shell pattern may refer to "a pattern of shells" or "a pattern on shells." Integrating the nouns into a meaningful representation for the compound as a whole is undoubtedly a central part of the interpretation process. A theory about the interpretation of novel compounds will therefore have to address the issue of how the relational ambiguity is resolved.

The interpretation of novel compounds requires the prior activation of the semantic representations of the constituent nouns. Not all meaning aspects of these nouns, however, are equally important for the interpretation of the compound. On the contrary, in both nouns, particular meaning aspects or components will have to be selected on which a meaningful integration of the meanings can be based. The selection of relevant meaning aspects

We wish to thank Estelle van Steen for running part of the experiments. The statistical assistance of Eric Schils and Lex Bouts is gratefully acknowledged. Correspondence should be addressed to Riet Coolen, Max Planck Institute for Psycholinguistics, Wundtlaan 1, 6525 XD Nijmegen, The Netherlands. of the nouns involves mapping two semantic representations to determine which aspects fit together. Meaningful relationships between the constituent nouns are formed on the basis of compatible meaning aspects. Different interpretations of the same novel compound will make different meaning aspects of the nouns highly relevant, as can be seen in the above example.

Contextual information often plays an important role in the interpretation of novel compounds. Information in the larger context will make clear how the novel compound is to be understood. For example, shell pattern will be interpreted differently in the sentences, "The stones were arranged in a shell pattern" and "Some pearl oysters have a beautiful shell pattern." The larger context of the compound contributes to its interpretation by providing cues for the selection of relevant meaning aspects (Murphy, 1990).

Many novel compounds, however, are readily interpretable in isolation (Downing, 1977; Gleitman \& Gleitman, 1970). For novel compounds such as melon pulp or wig fashion, one interpretation seems to suggest itself as self-evident. No contextual information seems necessary to induce this interpretation, and the resolution of the relational ambiguity in these compounds does not seem to pose any problems. Novel nominal compounds that can easily be interpreted without any contextual information are particularly interesting because they suggest that resolution of the relational ambiguity is achieved exclusively on the basis of the semantic representations of the constituent nouns (Coolen, Van Jaarsveld, \& Schreuder, 1991).

Semantic representations of the constituent nouns will become available either simultaneously or in rapid suc- 
cession. Because of temporal overlap (Kiger \& Glass, 1983 ) in the access of the semantic representations, activation of these representations may be interactive. More particularly, the activation of common or compatible meaning aspects may be reinforced, and the activation of mutually inconsistent meaning aspects may be inhibited. An interactive activation of semantic representations will aid the resolution of relational ambiguity, because the number of potentially relevant meaning aspects that have to be considered for interpretation will be reduced. Meaning aspects for which the activation is enhanced may be taken up more readily in the interpretative process, whereas meaning aspects that are inhibited may not be considered at all.

An alternative hypothesis is that the activation of semantic representations of the nouns is not interactive. Aspects of the semantic representations will become available regardless of their relevance for interpretation. Interpretative processes will have to consider meaning aspects of the constituent nouns more elaborately because activation of the semantic representations itself does not provide cues for interpretation. By limiting ourselves to compounds that are readily interpretable without context, our experiments were aimed at providing insight into the selection processes of relevant meaning aspects.

Interactive or independent activation of the semantic representations of constituent nouns can be tested by investigating the processing of ambiguous nouns in novel compounds. Interactive activation of meaning aspects may extend to different unrelated meanings of ambiguous nouns, of which only one is relevant for a meaningful interpretation of the compound. When both meanings of the ambiguous noun are found to be activated initially, meaning activation may be considered to be independent. When only the meaning relevant for interpretation is activated, there is evidence that the activation is interactive.

It will have been noticed that these rival hypotheses are closely related to different models that have been proposed for the effects of contexts on the activation of different meanings of ambiguous lexical items (Gorfein, 1989; Simpson, 1984, 1991; Small, Cottrell, \& Tanenhaus, 1988). According to the context-dependent model, context may result in activation of only the contextually relevant meaning. Autonomous models, however, propose that the initial activation of multiple meanings is independent of context. It will be seen that the interactive activation hypothesis for novel compounds is similar to the context-dependent model and that the independent activation hypothesis resembles the autonomous model.

Many studies concerned with the effects of sentence context on the activation of multiple meanings of lexical ambiguities have shown results that are consistent with the autonomous model (e.g., Onifer \& Swinney, 1981; Seidenberg, Tanenhaus, Leiman, \& Bienkowski, 1982; Swinney, 1979). Results of these studies generally indicate an initial activation of all meanings of the ambiguous word, followed by a rapid selection of the appropriate meaning. Activation of contextually irrelevant meanings is found even in contexts that clearly bias one particular meaning (see, e.g., Tanenhaus, Leiman, \& Seidenberg, 1979).

Several studies of on-line processing of lexical ambiguity, however, also support context-dependent access. Schvaneveldt, Meyer, and Becker (1976) presented their subjects with triplets of nouns in a lexical decision task. The second word of each triplet was lexically ambiguous, and the first and third nouns were related to either the same meaning or to different meanings of the ambiguous second noun. Responses to the third noun were facilitated when it was related to the same meaning as the first noun. Decision times for the third noun, however, did not differ from unrelated controls when the first and third nouns were related to different meanings. This result indicates that the first noun may have led to selective access of the meanings of the second noun. The observations of Schvaneveldt et al. are of particular interest because their experimental materials resemble novel compounds in important respects.

Context-dependent access has also been found in studies in which ambiguous words were embedded in sentence contexts. Simpson (1981) showed context-dependent retrieval in sentences that were strongly biased toward a particular meaning. Unfortunately, in his study (as in the Schvaneveldt et al., 1976, study), the intervals between the ambiguous word and related targets may have been too long to determine whether irrelevant meanings were initially activated (but see Simpson \& Kellas, 1989, for a recent replication with shorter delays). Using a delay of $0 \mathrm{msec}$ between ambiguous words and targets, Seidenberg and his associates (Seidenberg et al., 1982) demonstrated selective access for contextually relevant meanings when the preceding sentence contained words that were associatively or semantically related to that meaning. Tabossi (1988) obtained evidence for contextdependent access when the sentence context made particular aspects of dominant meanings highly salient. Simpson and Krueger (1991) have found selective access for dominant and subordinate meanings in strongly biasing contexts. It is at present unclear whether semantic characteristics of word and sentence contexts in which evidence for context-dependent activation has been obtained also extend to highly interpretable novel compounds.

For the purpose of our experiments, we constructed novel compounds whose obvious interpretation involved different meanings of ambiguous second nouns (e.g., $c e$ dar root or sine root). There was no meaningful interpretation that was based on the alternative meaning. Ambiguous second nouns were unbalanced homographs (cf. Duffy, Morris, \& Rayner, 1988; Hogaboam \& Perfetti, 1975; Rayner \& Duffy, 1986). In unbalanced homographs, one meaning is more frequent (the dominant meaning) than the other meaning (the subordinate meaning). Unambiguous nouns occurred as first nouns. ${ }^{2}$

We investigated the activation of distinct meanings of lexical ambiguities in a semantic priming paradigm (Simpson, 1984) by using a lexical decision task. Novel compounds served as primes, and associates of distinct mean- 
ings of the ambiguous compound member served as targets. We refer to targets related to dominant meanings as dominant targets and to targets related to subordinate meanings as subordinate targets. Mean latencies for dominant and subordinate targets preceded by dominant or subordinate compounds were compared with response latencies for the same targets preceded by unrelated control compounds. These control compounds also consisted of an unambiguous first noun and an ambiguous second noun, but they were difficult to interpret (e.g., gill scale). It will be noted that this procedure contrasts with most sentence studies, in which facilitation effects are determined by comparing mean latencies for related targets with control targets that involve different words. To investigate activation patterns for dominant and subordinate meanings over time, prime-target pairs were presented at three different stimulus onset asynchronies (SOAs; 340 , 540 , and $1,240 \mathrm{msec}$ ).

In formulating predictions of the two hypotheses, the nature of the lexical ambiguities needs to be taken into account. As mentioned above, ambiguous nouns were unbalanced homographs. Dominant meanings of unbalanced homographs are integrated faster in preceding sentence contexts than are subordinate meanings (Rayner \& Frazier, 1989; Simpson, 1984). When unbalanced ambiguities are presented in isolation, dominant meanings appear to be activated earlier than do subordinate meanings (Burgess \& Simpson, 1988; Simpson \& Burgess, 1985; Simpson \& Krueger, 1991). Apparently, the time course of the activation of distinct meanings varies as a function of their relative frequency. When these results extend to the processing of ambiguous nouns in novel compounds, facilitation effects for dominant targets may be expected at shorter SOAs than those for subordinate targets, due to the earlier availability of dominant meanings.

According to the interactive activation hypothesis, only the meaning of the ambiguous noun that is relevant for a meaningful interpretation will be activated. Thus, for compounds with interpretations based on the dominant meaning of the ambiguous noun (hence dominant compounds), only the dominant meaning will be activated; for compounds whose interpretation involves the subordinate meaning of the ambiguous noun (hence subordinate compounds), only the subordinate meaning will be activated. The interactive activation hypothesis therefore predicts that the presentation of dominant compounds as primes (e.g., cedar root) will cause facilitation only for dominant targets (e.g., carrot), and subordinate compounds (e.g., sine root) will cause facilitation effects only for subordinate targets (e.g., extract). Because of differences in the time course of activation of dominant and subordinate meanings, facilitation effects for targets preceded by dominant compounds may be found at shorter SOAs than for targets preceded by subordinate compounds.

The independent activation hypothesis predicts that initial activation of dominant and subordinate meanings will not be different for dominant and subordinate compounds.
No differences in facilitation effects for dominant or subordinate targets are expected, therefore, when they are preceded by dominant or subordinate compounds. Facilitation effects for dominant targets may be expected at shorter SOAs than those for subordinate targets. These earlier facilitation effects for dominant targets should, however, be the same for dominant or subordinate compounds. At longer SOAs, facilitation effects will only be obtained for targets related to the relevant meaning of the ambiguous noun.

\section{EXPERIMENT 1}

\section{Method}

Stimulus materials. For the construction of the novel compounds, 127 ambiguous nouns (noun-noun homographs) and 422 unambiguous nouns were selected. Each ambiguous noun had at least two separate entries in Groot Woordenboek der Nederlandse Taal (Van Dale, 1984), a comprehensive dictionary of the Dutch language.

With these nouns, 501 novel nominal compounds were made up. A compound was considered to be novel when it was not listed in the dictionary of Van Dale (1984) and the Dutch CELEX database based on 42 million tokens. ${ }^{3}$ Each novel compound consisted of two members: the first member was an unambiguous noun, and the second member was one of the 127 ambiguous nouns. Two types of experimental compounds were constructed: dominant compounds whose interpretations were based on the dominant meaning of the ambiguous noun (e.g., cederwortel [cedar root]) and subordinate compounds involving the subordinate meaning of the ambiguous noun (e.g., sinuswortel [sine root]). Some homographs were used for more than one instance of each compound type. From this large pool of novel compounds, 36 experimental stimuli were selected on the basis of the joint results of an association test for the constituent nouns and interpretability ratings for the compounds. Both tests are described below

An association test was used to determine the frequency of different meanings of the constituent nouns. All nouns used for the construction of the novel compounds were presented to 42 paid subjects who were students at Nijmegen University. The subjects were instructed to write down the first association that came to mind for each noun. Order of presentation was random. Eighteen ambiguous nouns were selected that clearly had a dominant meaning (more than $70 \%$ of the associates were related to this meaning) and a subordinate meaning (no more than $30 \%$ of the responses). For the 18 selected ambiguous nouns, the mean relative frequencies of dominant and subordinate meanings were $82.8 \%(S D=7.5)$ and $12.3 \%$ $(S D=8.2)$, respectively.

All 501 constructed compounds were rated for interpretability on a 7-point scale ( $1=$ very difficult to interpret; $7=$ very easy to interpret) by another group of 22 paid subjects. Novel compounds were presented in random order, and no time pressure was applied. On the basis of the mean rating scores, 1 dominant and 1 subordinate compound were selected for each of the 18 experimental homographs. The mean interpretability score for selected dominant and subordinate compounds was $5.4(S D=.8)$ for both.

Selected experimental compounds were between 7 and 15 letters long. Dominant and subordinate compounds were matched for mean letter length, for frequency, and for word length of the first noun. Mean letter length for dominant compounds was $10.4(S D=1.9)$; for subordinate compounds, it was $10.3(S D=2.0)$. Mean frequency of the first noun was 381 ( $S D=366$ ) for the dominant compounds and $380(S D=368)$ for the subordinate compounds (Burnage, 1990). Corresponding figures for the mean number of letters were 5.7 and 5.6, respectively ( $S D=1.0$ for both). Results of the 
association test were used to ascertain that first and second nouns of particular compounds had no associates in common.

A paraphrasing task was used to establish whether the interpretation of dominant and subordinate compounds involved the intended meaning of the ambiguous noun. Two lists of stimulus materials were constructed by assigning 9 dominant compounds and 9 subordinate compounds to each list. The 18 compounds in each list involved different homographs. Sixteen subjects were instructed to say out loud the first interpretation that came to mind for each compound. Eight subjects were given one set; the remaining 8 were given the other set. The results showed that $90 \%$ of the paraphrases for dominant compounds involved the dominant meaning of the ambiguous noun. For the subordinate compounds, $78 \%$ of the paraphrases involved the subordinate meaning of the homograph.

To establish activation of different meanings, we used a priming paradigm. Dominant and subordinate compounds as primes were followed by targets associatively related to the dominant or subordinate meaning of the ambiguous noun in the compound (dominant and subordinate targets). Dominant and subordinate targets were the most frequently produced associates for the distinct meanings of the homographs in the association task. Examples of different compound-target combinations are presented in Table 1.

For the unrelated compound-target combinations, dominant and subordinate targets were paired with a set of control compounds that involved a different set of 18 unbalanced homographs (e.g., gill scale). As for the experimental compounds, ambiguous nouns served as second members of the compounds. The mean interpretability score for the control compounds was 2.2 ( $S D=1.2$ ). Unrelated control and experimental compounds were matched for mean number of letters $(10.4 ; S D=1.9)$. They were also matched for the mean frequency $(381 ; S D=383)$ and the mean number of letters $(6.2 ; S D=1.2)$ of the first noun. A list of all experimental compound-target combinations, together with control compounds, is presented in the Appendix.

To determine whether associative relations between the ambiguous nouns and different targets were sufficiently strong to produce priming effects, a separate semantic priming experiment was conducted with a lexical decision task. Second members of the experimental and control compounds served as primes, followed by dorninant and subordinate targets. Presentation conditions for this experiment were identical to those described in the Procedure section below. The SOA between prime and target was $340 \mathrm{msec}$. Two lists of stimuli were constructed. Within each stimulus list, half of the experimental homographs were followed by dominant targets, and the remaining experimental homographs were followed by subordinate targets. When a homograph was followed by a dominant target in one list, the same homograph was followed by a subordinate target in the other list. For the unrelated condition, homographs from the control compounds were used as primes. In each list, every target occurred only once. Filler items were inserted to reduce the proportion of related prime-target pairs. Only half of the word targets were related to their primes. For the nonword trials, ambiguous nouns were used as primes, and orthographically legal

Table 1

Examples of Prime-Target Word Pairs in Experiment 1 (English Translations of the Dutch Words Appear in Parentheses)

\begin{tabular}{|c|c|c|c|}
\hline \multicolumn{2}{|c|}{ Prime } & \multicolumn{2}{|c|}{ Target } \\
\hline Dominance & Example & Dominant & Subordinate \\
\hline Dominant & $\begin{array}{l}\text { cederwortel } \\
\text { (cedar root) }\end{array}$ & $\begin{array}{l}\text { peen } \\
\text { (carrot) }\end{array}$ & $\begin{array}{l}\text { trekken } \\
\text { (extract) }\end{array}$ \\
\hline Subordinate & $\begin{array}{l}\text { sinuswortel } \\
\text { (sine root) }\end{array}$ & $\begin{array}{l}\text { peen } \\
\text { (carrot) }\end{array}$ & $\begin{array}{l}\text { trekken } \\
\text { (extract) }\end{array}$ \\
\hline Control & $\begin{array}{l}\text { kieuwschaal } \\
\text { (gill scale) }\end{array}$ & $\begin{array}{l}\text { peen } \\
\text { (carrot) }\end{array}$ & $\begin{array}{l}\text { trekken } \\
\text { (extract) }\end{array}$ \\
\hline
\end{tabular}

pseudowords were used as targets. Within each list, half of the targets consisted of nonword items. These items were the same for both stimulus lists. Fifteen paid subjects were randomly assigned to each of the two stimulus lists.

A significant main effect for relatedness was observed in the subject analysis $\left[F_{\mathrm{s}}(1,29)=25.10, M S_{\mathrm{e}}=1,334, p<.001\right]$ and in the item analysis $\left[F_{\mathrm{i}}(1,34)=17.11, M S_{\mathrm{e}}=1,167, p<.001\right]$. Shorter latencies were observed for related targets $(512 \mathrm{msec})$ than for unrelated targets $(546 \mathrm{msec}$ ). The effect for target (dominant or subordinate) was not significant $\left[F_{\mathrm{s}}(1,29)=1.83, M S_{\mathrm{e}}=665\right.$, $\left.p>10 ; F_{\mathrm{j}}<1\right]$. The interaction between relatedness and target was significant $\left[F_{\mathrm{s}}(1,29)=19.65, M S_{\mathrm{e}}=440, p<.001\right.$; $\left.F_{\mathrm{i}}(1,34)=4.07, M S_{\mathrm{e}}=1,167, p<.05\right]$. Separate analyses revealed that the relatedness effect $(49 \mathrm{msec})$ was highly significant for dominant targets $\left[F_{\mathrm{s}}(1,29)=35.16, M S_{\mathrm{e}}=1,082, p<.001\right.$; $\left.F_{\mathrm{i}}(1,17)=20.96, M S_{\mathrm{e}}=1,055, p<.05\right]$. The facilitation effect of $17 \mathrm{msec}$ for the subordinate targets was only significant in the subject analysis $\left[F_{\mathrm{s}}(1,29)=5.86, M S_{\mathrm{e}}=691, p<.05 ; F_{\mathrm{i}}(1,17)=\right.$ $\left.2.05, M S_{c}=1,279, p>.10\right]$. The results indicate that associative relatedness between the selected homographs and their dominant or subordinate targets was sufficiently strong to produce significant priming effects when they were presented as prime-target pairs.

Design. Stimulus onset asynchrony (SOA) between prime and target was set at three different intervals $(340,540$, and 1,240 msec) and was a between-subject factor. All other experimental manipulations were within-subject factors.

Six lists of stimulus materials were used in each SOA condition. Each list contained six dominant, six subordinate, and six control compounds. In each list, a particular ambiguous homograph occurred only once. Within one list, half of the experimental and control compounds were followed by dominant targets, and half were followed by subordinate targets. Across lists, all dominant and subordinate targets were preceded only once by their associated dominant, subordinate, or control compounds.

Each subject was presented with 144 trials. At each trial, a novel compound was presented as prime, followed by a word or nonword as target. In 72 trials, targets were words; in the other 72 trials, targets were nonwords. Of the 72 word trials, 18 involved experimental dominant and subordinate compounds and their controls. The remaining 54 word trials were filler items.

Of the 72 nonword trials, 36 compound primes had an unambiguous second noun, and the remaining 36 had an ambiguous noun as second member. Nonword items were the same in each stimulus list. To induce subjects to interpret the novel compounds, only one-sixth of all compounds were difficult to interpret.

Subjects. In total, 270 paid subjects were drawn from the subject pool of the Interfaculty Research Unit for Language and Speech (IWTS) at Nijmegen University. The subjects were randomly assigned to one of the three SOA conditions. Within a particular SOA condition, 15 subjects were randomly assigned to each of the six stimulus lists. None of the subjects had participated in any of the other experiments.

Procedure. Stimuli appeared in lowercase letters on a video display unit connected to an Olivetti M-24 personal computer. The subjects were seated in a room illuminated by subdued light. Each trial started with the display of an asterisk $\left({ }^{*}\right)$ two positions to the left of where the first letter of the prime was to appear. After $1 \mathrm{sec}$, the asterisk disappeared, and the novel compound was displayed for 300,500 , or $1,200 \mathrm{msec}$. After a blank screen of $40 \mathrm{msec}$, the target string appeared one line under the prime. It remained on the screen for a maximum of $1,500 \mathrm{msec}$, or until the subject pressed one of the response keys. The intertrial intervals were $3 \mathrm{sec}$. The subjects were instructed to read the novel compound carefully and to decide as quickly as possible whether the target was a word.

Because a wrong decision may affect the decision time for the subsequent stimulus, an extra filler stimulus was presented after each lexical decision error. For these purposes, 16 extra fillers were 
added to the stimulus set of 144 test trials. These optional fillers involved no repetition of any other item. The subjects were given 48 practice trials with the same characteristics as the experimental and filler items. Experimental sessions lasted about $25 \mathrm{~min}$.

\section{Results}

In this and subsequent experiments, the effects of very long latencies were reduced by establishing a cutoff point equal to 2.0 standard deviation units from subject and item means. Any outlying values were considered as errors and were left out. Outlying values amounted to $2.1 \%$ of all data. Stimuli for which outlying values were obtained were not repeated in the experiment. Reaction times (RTs) for incorrect responses were not included in the analyses. Mean lexical decision latencies and error percentages for compound-target combinations in different experimental conditions are presented in Table 2.

Mean reaction times were analyzed by a 2 (dominant or subordinate target) $\times 3$ (dominant, subordinate, or control compound) $\times 3$ (SOAs of 340,540 , and $1,240 \mathrm{msec}$ ) analysis of variance (ANOVA). Target and compound were within-subject factors, and SOA was a betweensubject factor. ANOVAs on subject and item means were carried out for RTs and percentages of error.

An overall ANOVA for the correct RTs showed that the main effect for target was significant in the subject analysis $\left[F_{\mathrm{s}}(1,267)=21.96, M S_{\mathrm{e}}=1,971, p<.001\right]$ but not in the item analysis $\left[F_{\mathrm{i}}(1,34)=1.37, M S_{\mathrm{e}}=\right.$ $7,233, p>.10]$. Type of compound was significant both in the subject and the item analysis $\left[F_{\mathrm{s}}(2,534)=5.80\right.$, $M S_{\mathrm{e}}=2,317, p<.01 ; F_{\mathrm{i}}(2,68)=5.17, M S_{\mathrm{e}}=713$, $p<.01]$. The main effect of SOA was not significant in either the subject or item analysis $\left[F_{\mathrm{s}}(2,267)=1.47\right.$, $M S_{\mathrm{c}}=13,225, p>.10 ; F_{\mathrm{i}}(2,68)=1.92, M S_{\mathrm{e}}=2,167$, $p>$.10]. The interaction between target and compound was significant in the subject and item analysis $\left[F_{\mathrm{s}}(2,534)=\right.$ $10.64, M S_{\mathrm{e}}=2,352, p<.001 ; F_{\mathrm{i}}(2,68)=6.22, M S_{\mathrm{e}}=$ $713, p<.01]$. No other two-way interaction was significant. The three-way interaction of SOA $\times$ target $\times$ compound was also not significant in both analyses.
The analysis of the error data showed a significant main effect for compound in the subject analysis $\left[F_{\mathrm{s}}(2,534)=\right.$ 4.32, $\left.M S_{\mathrm{e}}=.1, p<.05 ; F_{\mathrm{i}}<1\right]$. More errors were made for targets preceded by control compounds (3.4\%) than for targets preceded by dominant $(2.4 \%)$ or subordinate compounds $(2.5 \%)$. No other main effect or interaction was significant.

Planned pairwise comparisons were used to determine facilitation effects for dominant and subordinate targets separately for all three SOAs. An overview of these facilitation effects is presented in Table 3 . To determine facilitation effects, mean latencies for dominant and subordinate targets preceded by dominant or subordinate compounds were compared with latencies for the same targets preceded by control compounds.

SOA 340. A significant facilitation effect of $17 \mathrm{msec}$ was obtained for dominant targets preceded by dominant compounds in the subject analysis $\left[F_{\mathrm{s}}(1,89)=4.00\right.$, $\left.M S_{e}=2,623, p<.05\right]$. The effect was marginally significant in the item analysis $\left[F_{\mathrm{i}}(1,17)=4.26, M S_{\mathrm{e}}=\right.$ $651, p<.06$ ]. Response latencies for dominant targets preceded by subordinate compounds were not faster than latencies for the same targets preceded by control compounds $\left[F_{\mathrm{s}}<1 ; F_{\mathrm{i}}(1,17)=1.59, M S_{\mathrm{e}}=486, p>.10\right]$. No facilitation effect was observed for the subordinate targets preceded by subordinate compounds $\left[F_{\mathbf{s}}(1,89)=\right.$ $1.03, M S_{\mathrm{e}}=2,651, p>.10 ; F_{\mathrm{i}}<1$ ) or dominant compounds $\left(F_{\mathrm{s}}<1 ; F_{\mathrm{i}}<1\right)$.

More errors were made for dominant targets preceded by control compounds than by subordinate compounds $\left[F_{\mathrm{s}}(1,89)=4.63, M S_{\mathrm{e}}=.1, p<.05 ; F_{\mathrm{i}}(1,17)=1.76\right.$, $\left.M S_{\mathrm{e}}=.8, p>.10\right]$. Subordinate targets resulted in more errors when preceded by control compounds than by dominant compounds $\left[F_{\mathrm{s}}(1,89)=4.76, M S_{\mathrm{e}}=.1, p<.05\right.$; $\left.F_{\mathrm{i}}(1,17)=5.79, M S_{\mathrm{e}}=.3, p<.05\right]$.

SOA 540. A significant facilitation effect of $20 \mathrm{msec}$ was obtained for dominant targets preceded by dominant compounds in the subject analysis $\left[F_{\mathrm{s}}(1,89)=7.26\right.$, $\left.M S_{\mathrm{e}}=2,364, p<.01\right]$. As for the 340-msec SOA, this effect was again marginally significant in the item analy-

Table 2

Mean Decision Latencies (in Milliseconds) and Error Percentages in Experiment 1 for Related and Unrelated Word Pairs at Three Different SOAs (in Milliseconds)

\begin{tabular}{|c|c|c|c|c|c|c|}
\hline \multirow[b]{3}{*}{ Target } & \multicolumn{6}{|c|}{ Prime } \\
\hline & \multicolumn{4}{|c|}{ Related } & \multicolumn{2}{|c|}{ Unrelated } \\
\hline & Dominant & $\%$ Error & Subordinate & $\%$ Error & Control & $\%$ Error \\
\hline \multicolumn{7}{|c|}{$\mathrm{SOA}=340$} \\
\hline Dominant & 529 & 2.6 & 537 & 1.1 & 546 & 3.7 \\
\hline Subordinate & 550 & 1.1 & 546 & 2.2 & 553 & 4.1 \\
\hline \multicolumn{7}{|c|}{$S O A=540$} \\
\hline Dominant & 530 & 2.6 & 545 & 2.2 & 550 & 1.9 \\
\hline Subordinate & 554 & 3.3 & 540 & 4.4 & 554 & 4.4 \\
\hline \multicolumn{7}{|c|}{$\mathrm{SOA}=1,240$} \\
\hline Dominant & 515 & 3.0 & 530 & 3.3 & 537 & 1.9 \\
\hline Subordinate & 546 & 1.9 & 528 & 1.5 & 547 & 4.4 \\
\hline
\end{tabular}


Table 3

Priming Effects for RT (in Milliseconds) and Error Percentages for Different Prime-Target Pairs at Three Different SOAs (in Milliseconds) in Experiment 1

\begin{tabular}{|c|c|c|c|c|}
\hline \multirow[b]{2}{*}{ Target } & \multicolumn{4}{|c|}{ Prime } \\
\hline & Dominant & $\%$ Error & Subordinate & $\%$ Error \\
\hline \multicolumn{5}{|c|}{$\mathrm{SOA}=340$} \\
\hline Dominant & $17 *$ & 1.1 & 9 & $2.6^{*}$ \\
\hline Subordinate & 3 & $3.0^{*}$ & 7 & 1.9 \\
\hline \multicolumn{5}{|c|}{$\mathrm{SOA}=540$} \\
\hline Dominant & $20^{*}$ & -0.7 & 5 & -0.3 \\
\hline Subordinate & 0 & 1.1 & $14 \dagger$ & 0 \\
\hline \multicolumn{5}{|c|}{$\mathrm{SOA}=1,240$} \\
\hline Dominant & $22^{*}$ & -1.1 & 7 & -1.4 \\
\hline Subordinate & 1 & 2.5 & $19^{*}$ & $2.9 *$ \\
\hline
\end{tabular}

sis $\left[F_{\mathrm{i}}(1,17)=4.31, M S_{\mathrm{e}}=790, p<.06\right]$. No facilitation effect was observed for dominant targets when they were preceded by subordinate compounds $\left(F_{\mathrm{s}}<1 ; F_{\mathrm{i}}<\right.$ 1). The facilitation effect of $14 \mathrm{msec}$ for subordinate targets preceded by subordinate compounds was marginally significant in the subject analysis $\left[F_{\mathrm{s}}(1,89)=3.80\right.$, $M S_{\mathrm{e}}=2,051, p<.06 ; F_{\mathrm{i}}(1,17)=2.08, M S_{\mathrm{e}}=883$, $p>$.10]. Subordinate targets preceded by dominant compounds did not show significant priming effects $\left(F_{\mathrm{s}}<1\right.$; $\left.F_{\mathrm{i}}<1\right)$. No significant differences in error percentages were observed.

SOA 1,240. A significant facilitation effect of $22 \mathrm{msec}$ was obtained for dominant targets preceded by dominant primes $\left[F_{\mathrm{s}}(1,89)=7.70, M S_{\mathrm{e}}=2,368, p<.01\right.$; $\left.F_{\mathrm{i}}(1,17)=10.12, M S_{\mathrm{e}}=403, p<.01\right]$. Dominant targets preceded by subordinate compounds did not show a facilitation effect $\left(F_{\mathrm{s}}<1 ; F_{\mathrm{i}}<1\right)$. Subordinate targets preceded by subordinate compounds yielded a facilitation effect of $19 \mathrm{msec}\left[F_{\mathrm{s}}(1,89)=4.19, M S_{\mathrm{e}}=2,542\right.$, $\left.p<.05 ; F_{\mathrm{i}}(1,17)=9.35, M S_{\mathrm{e}}=324, p<.01\right]$. No facilitation was observed for these targets when they were preceded by dominant compounds $\left(F_{\mathrm{s}}<1 ; F_{\mathrm{i}}<1\right)$.

Subordinate targets preceded by control compounds resulted in more errors than did the same targets preceded by subordinate compounds $\left[F_{\mathrm{s}}(1,89)=4.14, M S_{\mathrm{e}}=.1\right.$, $\left.p<.05 ; F_{\mathrm{i}}(1,17)=2.29, M S_{\mathrm{e}}=.8, p>.10\right]$.

\section{Discussion}

Different predictions were made from the interactive and independent activation hypotheses. The interactive activation hypothesis assumes that only the meaning of the ambiguous noun that is relevant for the interpretation of the compound will be activated. Facilitation effects are therefore predicted for dominant targets preceded by dominant compounds and for subordinate targets preceded by subordinate compounds. The independent activation hypothesis supposes that dominant and subordinate meanings will be activated for both dominant and subordinate compounds.
The overall pattern of facilitation effects for the RT data in Table 3 clearly is consistent with the interactive activation hypothesis. Only relevant meanings of the ambiguous compound members appear to be accessed. At the SOAs of 340,540 , and $1,240 \mathrm{msec}$, facilitation effects were obtained for dominant targets when they were preceded by dominant compounds but not when they were preceded by subordinate compounds. For subordinate targets, significant priming effects were observed when they were preceded by subordinate compounds (SOAs of 540 and $1,240 \mathrm{msec}$ ) but not when they were preceded by dominant compounds.

It may be argued that this interpretation of the facilitation pattern in the RT data needs to be qualified because of the error data. In particular, at the 340-msec SOA, no significant priming effect for the RT was observed for dominant targets when they were preceded by subordinate primes, but this condition resulted in significantly fewer errors than for the corresponding control condition. The same result was obtained for the subordinate targets when they were preceded by dominant primes. If error rates had been equal for related and control conditions, RTs might have been faster for the related conditions than for the unrelated controls, and significant priming effects in these conditions might have been obtained. Thus, the results for the 340-msec SOA may indicate a speed-accuracy tradeoff. However, we regard this possibility as rather unlikely. For the three SOA conditions together, the data do not indicate a systematic speed-accuracy tradeoff. At the 540-msec SOA, no significant differences in error percentages were observed. At the 1,240-msec SOA, only one significant difference in error percentages was obtained, and this involved a different condition from the ones that showed significant error reductions at the 340msec SOA. We see no obvious reasons to assume a speedaccuracy tradeoff for only the 340-msec SOA condition.

Other objections may be put forward against the interpretation of the RT results presented above. It may be argued that a visual presentation of compounds that are between 7 and 15 letters long makes it rather difficult to assess activation of different meanings prior to target presentation (Tabossi, 1991). Activation of both meanings of an ambiguous noun has been shown to last for only a short period of time (Lucas, 1987; Seidenberg et al., 1982). Especially for the shorter compounds, an SOA of $340 \mathrm{msec}$ may have been too long to demonstrate initial activation of both meanings of the ambiguous compound members.

As Simpson and Krueger (1991) have pointed out, this objection implies a rather unlikely time course of activation for subordinate meanings. After initial activation of subordinate meanings at some SOA shorter than $340 \mathrm{msec}$, these meanings would become deactivated at the $340-\mathrm{msec}$ SOA, with subsequent reactivation at the 540-msec SOA. In addition, it should be noted that an SOA of $340 \mathrm{msec}$ comes close to the minimum amount of time needed to visually process the compounds. 
O'Regan, Lévy-Schoen, Pynte, and Brugaillère (1984) have shown that the mean gaze duration for French nouns of 7 to 11 letters long ranges between 400 and $500 \mathrm{msec}$ when these words are fixated on the third letter (see also O'Regan, 1984).

A second objection has to do with differential intralexical priming effects for the first members of the compounds and different targets. The results of the association task described in the Methods section of Experiment 1 were used to ascertain that first nouns were not related associatively to targets. Still, dominant targets may be more strongly related semantically to the first members of dominant compounds than to the first members of subordinate compounds. Such differences in semantic relatedness could explain why facilitation effects for dominant targets were observed for dominant compounds but not for subordinate compounds. Similar differences may have affected subordinate targets and subordinate compounds.

Experiment 2 was conducted to determine if such unexpected differences in semantic relatedness between first members and targets could explain our results. In a semantic priming paradigm, first members of dominant and subordinate compounds were presented as primes, followed by the same dominant and subordinate targets used in Experiment 1. Latencies for dominant targets preceded by first members of dominant compounds should not differ from latencies for the same targets when they are preceded by first members of subordinate compounds. The same prediction holds for subordinate targets. If, however, semantic relatedness is different for first members, both types of novel compounds, and different targets, larger priming effects may be expected for dominant targets when they are preceded by first members of dominant compounds. Similarly, priming effects may be larger for subordinate targets when they are preceded by first members of subordinate compounds.

\section{EXPERIMENT 2}

\footnotetext{
Method

Materials and Design. Two lists of 144 stimuli were constructed. In each stimulus list, the first members of the 18 dominant compounds and 18 subordinate compounds used in Experiment 1 served as primes, followed by the same targets that were used in Experiment 1 . The first members of the dominant and subordinate compounds were paired with dominant and subordinate targets in different lists. In each list, half of the 36 experimental prime-target combinations were concordant (first members of dominant compounds followed by dominant targets or first members of subordinate compounds followed by subordinate targets), and the other half were discordant (first members of dominant compounds followed by subordinate targets or first members of subordinate compounds followed by dominant targets). Thus, in each stimulus list, each prime and target occurred only once. An additional set of 36 word trials was used as filler material. For the construction of the 72 nonword trials, the materials were the same as in Experiment 1, with only the first noun of the novel compounds serving as primes. Filler word trials and nonword trials were the same for both stimulus lists. A set of $\mathbf{4 8}$ practice items was also constructed.
}

Procedure and Subjects. Experimental procedures were the same as in Experiment 1. SOA was set at $340 \mathrm{msec}$. Experimental sessions lasted about $20 \mathrm{~min}$.

Thirty subjects of the subject pool of the IWTS at Nijmegen University participated in this experiment. None of them had participated in any of the previous experiments. The subjects were paid for their participation. Fifteen subjects were randomly assigned to each of the two stimulus lists.

\section{Results and Discussion}

The ANOVA for the latencies showed no significant main effects for the first nouns of different types of compounds $\left(F_{\mathrm{s}}<1 ; F_{\mathrm{i}}<1\right)$ and for dominant or subordinate targets $\left(F_{\mathrm{s}}<1 ; F_{\mathrm{i}}<1\right)$. The interaction between these factors also did not reach significance $\left[F_{\mathrm{s}}(1,29)=1.13\right.$, $\left.M S_{c}=522, p>.10 ; F_{\mathrm{i}}<1\right]$. Mean latencies and error percentages are presented in Table 4.

In the analyses of error percentages, the effects of first nouns of compounds $\left[F_{\mathrm{s}}(1,29)=2.22, M S_{\mathrm{e}}=.2, p>\right.$ $\left..10 ; F_{\mathrm{i}}<1\right]$, targets $\left(F_{\mathrm{s}}<1 ; F_{\mathrm{i}}<1\right)$, and their interaction $\left[F_{\mathrm{s}}<1, F_{\mathrm{i}}(1,34)=2.03, M S_{\mathrm{e}}=1.5, p>.10\right]$ were not significant.

The results show that selective activation of only the relevant meaning of the ambiguous compound members in Experiment 1 cannot be attributed to differences in semantic relatedness between first members of dominant and subordinate compounds and their targets.

A salient aspect of the results of Experiment 1 is that subordinate meanings tended to become available later in time than did dominant meanings. Significant priming effects for dominant meanings were already obtained at the 340-msec SOA, but significant priming effects for subordinate meanings were only obtained with a delay of at least $540 \mathrm{msec}$. This result is in line with other studies (Burgess \& Simpson, 1988; Simpson \& Burgess, 1985; Simpson \& Krueger, 1991) that have shown that the time course of activation of different meanings of homographs is frequency dependent. When meanings differ markedly in frequency, dominant meanings appear to be activated sooner than subordinate meanings.

At the 340-msec SOA, dominant targets were facilitated when they were preceded by dominant compounds but not when they were preceded by subordinate compounds. Since both classes of novel compounds were matched for interpretability and overall letter length, as well as for frequency and word length of the first compound member, this differential priming effect can only be attributed to

Table 4

Mean Decision Latencies (in Milliseconds) and Percentages of Errors for Dominant and Subordinate Targets Preceded by First Members of Dominant and Subordinate Compounds in Experiment 2

\begin{tabular}{lcccc}
\hline & \multicolumn{4}{c}{ Target } \\
\cline { 2 - 5 } \multicolumn{1}{c}{ Prime } & Dominant & \% Error & Subordinate & \% Error \\
\hline Dominant & 529 & 5.2 & 526 & 4.1 \\
Subordinate & 531 & 3.7 & 532 & 5.6 \\
\hline
\end{tabular}


interpretative processing. Apparently, dominant compounds are already interpreted at the SOA of $340 \mathrm{msec}$, but interpretation of subordinate compounds is still in progress. Subordinate compounds appear to be interpreted at the 540-msec SOA, because at this SOA, subordinate targets were facilitated when preceded by subordinate compounds but not when preceded by dominant compounds.

An alternative explanation of the differential speed of interpretation of dominant and subordinate compounds may be proposed that has to do with relations between the constituent nouns in both types of novel compounds. Both meanings of the ambiguous noun may be activated simultaneously, but dominant compounds will be interpreted faster than subordinate compounds when first members of dominant compounds are more strongly related to the ambiguous second noun than to first members of subordinate compounds. Thus, instead of earlier availability of dominant meanings, stronger intralexical relations between members of dominant compounds may have caused a faster interpretation of dominant compounds.

Experiment 3 was conducted to determine whether dominant and subordinate compounds differed in the semantic relatedness between first and second members. In this experiment, first members of different compounds served as primes, and ambiguous second nouns served as targets. According to the alternative explanation described above, mean latencies for targets involving dominant compounds should be shorter than mean latencies for targets involving subordinate compounds. If, on the other hand, early activation of dominant meanings of the ambiguous nouns underlies the fast interpretation of dominant compounds, mean latencies for targets involving dominant compounds should not differ from latencies for targets involving subordinate compounds.

\section{EXPERIMENT 3}

\footnotetext{
Method

Materials and Design. The first members of experimental dominant and subordinate compounds in Experiment 1 served as primes, and the second members (i.e., the ambiguous nouns) served as targets. Targets were, of course, the same for prime-target combinations involving dominant and subordinate compounds. Two stimulus lists were constructed. When a target was paired with the first member of a dominant compound in one list, it was paired with the first member of the corresponding subordinate compound in the other list. Thus, in each list, every target occurred only once. Within each list, 9 prime-target combinations were based on dominant compounds, and 9 were based on subordinate compounds. In each stimulus list, prime-target combinations were included that consisted of first members of the 18 control compounds as primes and their corresponding homographs as targets.

An additional set of 36 word trials was constructed on the basis of filler compounds with two unambiguous constituent members used in Experiment 1. First members served as primes, and second members served as targets. For the 72 nonword trials, the novel compounds and targets were the same as in Experiment 1. First members of the novel compounds served as primes. Each list contained the same filler word trials and nonword trials.
}

Procedure and Subjects. Experimental conditions were the same as in Experiment 1, except that first members of novel compounds functioned as primes and their second members as targets. SOA was set at 340 msec. Extra filler items were introduced, contingent on errors. Experimental sessions lasted about $20 \mathrm{~min}$.

Thirty subjects of the subject pool of the IWTS at Nijmegen University participated in this experiment. None of them had participated in any of the previous experiments. The subjects were paid for their participation. Fifteen subjects were randomly assigned to each of the stimulus lists.

\section{Results and Discussion}

Mean latencies for second members of dominant compounds $(529 \mathrm{msec})$ did not differ from mean latencies for second members of subordinate compounds $(537 \mathrm{msec}$; $\left.F_{\mathrm{s}}<1 ; F_{\mathrm{i}}<1\right)$. Error percentages for second members of dominant compounds $(6.7 \%)$ and subordinate compounds $(5.2 \%)$ also did not differ $\left(F_{\mathrm{s}}<1 ; F_{\mathrm{i}}<1\right)$.

These results show that the faster interpretation of dominant compounds cannot be attributed to differences in semantic relatedness between first and second members of dominant and subordinate compounds. Therefore, it may be concluded that dominant compounds are interpreted before subordinate compounds as a result of the early activation of dominant meanings of ambiguous compound members relative to the subordinate meanings.

\section{GENERAL DISCUSSION}

Although the majority of studies of the processing of lexical ambiguity have shown activation of different meanings to be context-independent (Onifer \& Swinney, 1981; Seidenberg et al, 1982; Simpson, 1984; Swinney, 1979), Experiment 1 does not stand alone in providing evidence for context-dependent access. Tabossi (1988) obtained support for selective access of dominant meanings in sentence contexts that made particular features of these meanings highly salient. In a recent study, Kellas, Paul, Martin, and Simpson (1991) reported results that extend these findings to subordinate meanings. They obtained selective priming effects for dominant, as well as for subordinate, meanings of homographs in sentence contexts that made particular features of these meanings highly salient.

Both Tabossi (1988) and Kellas et al. (1991) attribute selective access to specific semantic characteristics of the sentence contexts they used. When the preceding context imposes sufficiently strong constraints on the meaning of upcoming words, effects of selective access will be observed. Tabossi suggests that one way in which contexts may impose such constraints is by priming semantic features of the upcoming word (see also Schwanenflugel \& LaCount, 1988). Even though presentation conditions of words in sentences differ from those of words in novel compounds, similar mechanisms may be involved to explain selective access in both cases. In the case of novel compounds, these mechanisms will operate under specific time constraints.

As noted earlier, the semantic representations of the nouns in novel compounds will be activated (partly) simul- 
taneously. Because of this temporal overlap, mutual constraints on the activation of particular meaning aspects may become operative. The notion of temporal overlap in accessing semantic representations was originally proposed by Kiger and Glass (1983) to explain the occurrence of backward priming effects. Peterson and Simpson (1989) have recently provided a more elaborate account of backward priming mechanisms that may also apply to the processing of compound nouns. In their study, they used unidirectional prime-target pairs that were backwardly related (e.g., baby-stork) in a cross-modal naming and lexical decision experiment. When the interstimulus interval (ISI) was $0 \mathrm{msec}$, priming effects were observed in the naming and lexical decision task, but evidence for backward priming was obtained with an ISI of $200 \mathrm{msec}$ only in the lexical decision task.

To explain their results, Peterson and Simpson (1989) reasoned as follows. If the target is presented before processing of the prime is complete ( $0-\mathrm{msec}$ ISI), the target could guide further processing of the prime and determine the development of the final representation of the prime. Peterson and Simpson specifically suggest that relevant aspects of the target could affect the evolving representation of the prime in such a way that it would be compatible with the target. The modified concept of the prime could in turn facilitate the ongoing processing of the target, resulting in a backward priming effect. However, if the target is presented after the processing of the prime is complete (200-msec ISI), the evolving representation of the prime will not be influenced by the target. The evidence for backward priming at the 200-msec ISI in the lexical decision task will be attributed to postlexical decision processes, which do not play a role in the naming task.

It will be seen that this account may also be applied to the processing of the semantic representations of constituent nouns in novel compounds. Interactive activation will enhance the activation of compatible meaning aspects and may prevent activation of incompatible meaning aspects. These interactions between evolving semantic representations may explain why only meanings that are relevant for meaningful interpretation are activated. Inspection of the stimulus materials listed in the Appendix support this suggestion. Consider, for example, the dominant compound zenuwbuil (nerve swelling), in which the meaning aspect "part of body" is highly compatible for the two nouns. For the subordinate compound tapijtstaal (carpet sample), the meaning aspect "soft" of carpet may prevent the activation of the dominant meaning of staal (steel) because it contains the opposite feature "hard."

Priming effects may not only reflect activation processes but also integrative processes between prime (compound meaning) and target that affect decision processes (Neely \& Keefe, 1989). Larger priming effects may be expected when prime and target are integrated more easily. It is difficult to rule out completely such an account of our results, but one prediction of this account was not confirmed. When priming effects were based on the integration between the interpreted compound and the target, priming effects should also have been found at the $340-\mathrm{msec}$ SOA for the subordinate targets when they were preceded by subordinate compounds. Contrary to this account, no significant priming effect was observed; therefore, an activation account may be preferred.

It should be noted that priming effects in Experiment 1 in the 340-msec SOA condition were considerably smaller than in the validation experiment that was described in the Methods section of Experiment 1. Although a comparison between the results of these experiments should proceed carefully because of the different characteristics of the stimulus materials, we suggest that interactive activation may account for this reduction in the size of the priming effect. The relatedness between the ambiguous second noun and the target may have weakened because of the modifying effects of the first noun with respect to the ambiguous noun.

The results of Experiment 1 suggested that dominant meanings may become available sooner than subordinate meanings. Similar differences in activation may apply to dominant and nondominant aspects within a particular meaning. Dominant meaning aspects of particular meanings may become available sooner than nondominant meaning aspects (but see Whitney, McKay, Kellas, \& Emerson, 1985).

The selection of a meaningful semantic relationship between compound members may depend on the dominance of compatible meaning aspects. Dominant meaning aspects will be considered earlier in the interpretation process than will subordinate ones, and meaningful relations involving dominant meaning aspects will be computed before semantic relationships in which subordinate meaning aspects are involved. Interpretations of novel compounds that are easy to interpret in isolation will therefore involve mainly dominant meaning aspects of both compound members, whereas interpretations of novel compounds that are difficult to interpret without context will be based on nondominant meaning aspects. When compatible meaning aspects are of low dominance, more than one plausible interpretation of the same compound may be derived. Consistent with these speculations, Coolen et al. (1991) showed that paraphrases of meanings of isolated novel compounds that were difficult to interpret displayed more diversity than did paraphrases of novel compounds that were easy to interpret.

Interactive activation can be incorporated in Murphy's $(1988,1990)$ concept specialization model for the interpretation of novel compounds. This model supposes that the modifying concept (the first member of the compound) fills a slot in the conceptual schema of the head noun (the second member of the compound). For the selection of particular slots, it is assumed that world knowledge is consulted, but the model does not specify exactly how world knowledge is involved in this process. In particular, it does not answer the question of how the relevance of specific pieces of world knowledge is determined. Our results suggest that the selection of particular slots is based on the relative dominance of meaning aspects of the constituent 
nouns. The selection process may therefore be regarded as more intimately linked to the semantic representations of the constituent nouns than is envisioned in the concept specialization model. As the results of Murphy (1990) indicate, context can make particular meaning aspects of the constituent nouns more salient and may in this way contribute to the interpretation of novel compounds. For highly interpretable compounds, however, contextual information is less important, because these compounds are based on dominant meaning aspects of the constituent nouns. The enhanced activation of relevant meaning aspects caused by interactive processing of the semantic representations of the nouns may well be the basis for the high interpretability of these compounds.

\section{REFERENCES}

BAUER, L. (1983). English word-formation. Cambridge: Cambridge University Press.

BoAse-BeIer, J. (1987). Poetic compounds (pp. 37-84). Tübingen, Germany: Max Niemeyer Verlag.

BuRgess, C., \& Simpson, G. B. (1988). Cerebral hemispheric mechanisms in the retrieval of ambiguous word meanings. Brain \& Language, 33, 86-103.

Burnage, G. (1990). CELEX: A guide for users. Nijmegen, The Netherlands: University of Nijmegen.

Coolen, R., van JaArsveld, H. J., \& Schreuder, R. (1991). The interpretation of isolated novel nominal compounds. Memory \& Cognition, 19, 341-352.

Downing, P. (1977). On the creation and use of English compound nouns. Language, 53, 810-842.

DuFFY, S. A., MorRIS, R. K., RAYNer, K. (1988). Lexical ambiguity and fixation times in reading. Journal of Memory \& Language, 27, 429-446.

Gleitman, L. R., \& Gleitman, H. (1970). Phrase and paraphrase: Some innovative uses of language. New York: Norton.

GoRfEIN, D. S. (1989). Resolving semantic ambiguity. New York: Springer-Verlag.

Hogaboam, T. W., \& Perfetti C. A. (1975). Lexical ambiguity and sentence comprehension. Journal of Verbal Learning \& Verbal Behavior, 14, 265-274.

Kellas, G., Paul, S. T., Martin, M., \& Simpson, G. B. (1991). Contextual feature activation and meaning access. In G. B. Simpson (Ed.), Understanding word and sentence ( $\mathrm{pp}$. 47-71). Amsterdam: NorthHolland/Elsevier Science Publishers.

Kiger, J. I., \& Glass, A. L. (1983). The facilitation of lexical decisions by a prime occurring after the target. Memory \& Cognition, 11, 356-365.

LEES, R. B. (1970). Problems in the grammatical analysis of English nominal compounds. In M. Bierwisch \& K. E. Heidolph (Eds.), Progress in linguistics (pp. 174-186). The Hague: Mouton.

LEVI, J. N. (1978). The syntax and semantics of complex nominals. London: Academic Press.

LuCAS, M. M. (1987). Frequency effects on the processing of ambiguous words in sentence contexts. Language \& Speech, 30, 25-46.

MurPhy, G. L. (1988). Comprehending complex concepts. Cognitive Science, 12, 529-562.

MURPHY, G. L. (1990). Noun phrase interpretation and conceptual combination. Journal of Memory \& Language, 29, 259-288.

NeEly, J. H., \& KeEFE, D. E. (1989). Semantic context effects on visual word recognition: A hybrid prospective/retrospective processing theory. In G. H. Bower (Ed.), The psychology of learning and motivation: Advances in research and theory (Vol. 24, pp. 207-248). New York: Academic Press.

ONIFER, W., \&WinNey, D. A. (1981). Accessing lexical ambiguities during sentence comprehension: Effects of frequency of meaning and contextual bias. Memory \& Cognition, 9, 225-236.
O'Regan, J. K. (1984). How the eye scans isolated words. In A. G. Gale \& F. Johnson (Eds.), Theoretical and applied aspects of eye movement research (pp. 159-168). Amsterdam: North-Holland/ Elsevier Science Publishers.

O'Regan, J. K., Levy-Schoen, A., Pynte, J., \& Brugaillère, B. (1984). Convenient fixation location within isolated words of different length and structure. Journal of Experimental Psychology: Human Perception \& Performance, 10, 250-257.

Peterson, R. R., \& Simpson, G. B. (1989). Effect of backward priming on word recognition in single-word and sentence contexts. Journal of Experimental Psychology: Learning, Memory, \& Cognition, 15, 1020-1032.

RAYNER, K., \& DUFFY, S. A. (1986). Lexical complexity and fixation times in reading: Effects of word frequency, verb complexity, and lexical ambiguity. Memory \& Cognition, 14, 191-201.

Rayner, K., \& Frazier, L. (1989). Selection mechanisms in reading lexically ambiguous words. Journal of Experimental Psychology: Learning, Memory, \& Cognition, 15, 779-790.

Schvaneveldt, R. W., Meyer, D. E., \& Becker, C. A. (1976). Lexical ambiguity, semantic context, and visual word recognition. Journal of Experimental Psychology: Human Perception \& Performance, 2, 243-256.

Schwanenflugel, P. J., \& LaCount, K. L. (1988). Semantic relatedness and the scope of facilitation for upcoming words in sentences. Journal of Experimental Psychology: Learning, Memory, \& Cognition, 14, 344-354.

Seidenberg, M. S., Tanenhaus, M. K., Leiman, J. M., \& BienKowSKI, M. (1982). Automatic access of the meanings of ambiguous words in context: Some limitations of knowledge-based processing. Cognitive Psychology, 14, 489-537.

Simpson, G. B. (1981). Meaning dominance and semantic context in the processing of lexical ambiguity. Journal of Verbal Learning \& Verbal Behavior, 20, 120-136.

Simpson, G. B. (1984). Lexical ambiguity and its role in models of word recognition. Psychological Bulletin, 96, 316-340.

SIMPSON, G. B. (Ed.) (1991). Understanding word and sentence. Amsterdarn: North-Holland/Elsevier Science Publishers.

Simpson, G. B., \& Burgess, C. (1985). Activation and selection processes in the recognition of ambiguous words. Joumal of Experimental Psychology: Human Perception \& Performance, 11, 28-39.

Simpson, G. B., \& Kellas, G. (1989). Dynamic contextual processes and lexical access. In D. S. Gorfein (Ed.), Resolving semantic ambiguity (pp. 40-56). New York: Springer-Verlag.

SimpSon, G. B., \& KRUEGER, M. A. (1991). Selective access of homograph meanings in sentence contexts. Journal of Memory \& Language, 30, 627-643.

Small, S. L., Cottrell, G. W., \& Tanenhaus, M. K. (1988). Lexical ambiguity resolution: Perspectives from psycholinguistics, neuropsychology and artificial intelligence. San Mateo, CA: Morgan Kaufmann.

SWINNEY, D. A. (1979). Lexical access during sentence comprehension: (Re)consideration of context effects. Journal of Verbal Learning \& Verbal Behavior, 18, 645-659.

TABOssI, P. (1988). Accessing lexical ambiguity in different types of sentential contexts. Journal of Memory \& Language, 27, 324-340.

TABossi, P. (1991). Understanding words in context. In G.B. Simpson (Ed.), Understanding word and sentence ( $\mathrm{pp} .1-22$ ). Amsterdam: North-Holland/Elsevier Science Publishers.

Tanenhaus, M. K., Leiman, J. M., \& Seidengerg, M. S. (1979). Evidence for multiple stage in the processing of ambiguous words in syntactic contexts. Journal of Verbal Leaming \& Verbal Behavior, $18,427-440$.

VAN DALE (1984). Groot Woordenboek der Nederlandse Taal. Utrecht/Antwerpen: Van Dale Lexicografie.

Whitney, P., McKay, T., Kellas, G., a Emerson, W. A. (1985). Semantic activation of noun concepts in context. Joumal of Experimental Psychology: Learning, Memory, \& Cognition, 11, 126-135.

WISNIEWSKI, E. J., \& GENTNER, D. (1991). On the combinatorial semantics of noun pairs: Minor and major adjustments. In G. B. Simpson (Ed.), Understanding word and sentence (pp. 241-285). Amsterdam: North-Holland/Elsevier Science Publishers. 
NOTES

1. We use the term compound as a shorthand for the more restricted set of novel noun-noun compounds. In our experiments, Dutch materials and subjects were used. Unlike English novel compounds, most Dutch novel compounds are written without spacing or hyphenation, which makes them in orthographic respects indistinguishable from lexicalized compounds.
2. We assume that our results will extend to the processing of ambiguous first nouns, but it cannot be ruled out that additional research may uncover some differences in the processing of first and second nouns due to their different semantic roles in the interpretation of the compounds. In the novel compounds we constructed, the second noun is always the semantic head of the compound, and the first noun is the modifying element (e.g., a cedar root is a kind of root). This class of nominal compounds is usually referred to as endocentric (Bauer, 1983).

3. CELEX Dutch Database Rel. N2.7, Centre for Lexical Information, Nijmegen, The Netherlands.

\section{APPENDIX}

Stimuli From Experiment 1: The First Line of Each Contains the Dutch Words That Were Used and the Second Line the English Equivalents

\begin{tabular}{|c|c|c|c|c|}
\hline \multicolumn{3}{|c|}{ Prime } & \multicolumn{2}{|c|}{ Target } \\
\hline Dominant & Subordinate & Control & Dominant & Subordinate \\
\hline $\begin{array}{l}\text { designbloem } \\
\text { design flower }\end{array}$ & $\begin{array}{l}\text { banketbloem } \\
\text { pastry flour }\end{array}$ & $\begin{array}{l}\text { magneetorde } \\
\text { magnetic order }\end{array}$ & $\begin{array}{l}\text { blad } \\
\text { leaf }\end{array}$ & $\begin{array}{l}\text { meel } \\
\text { farina }\end{array}$ \\
\hline $\begin{array}{l}\text { zenuwbuil } \\
\text { nerve swelling }\end{array}$ & $\begin{array}{l}\text { soepbuil } \\
\text { soup bag }\end{array}$ & $\begin{array}{l}\text { genadehit } \\
\text { mercy song/horse }\end{array}$ & $\begin{array}{l}\text { bult } \\
\text { lump }\end{array}$ & $\begin{array}{l}\text { zak } \\
\text { sack }\end{array}$ \\
\hline $\begin{array}{l}\text { junkcel } \\
\text { junky cell }\end{array}$ & $\begin{array}{l}\text { mergcel } \\
\text { marrow cell }\end{array}$ & $\begin{array}{l}\text { egelpot } \\
\text { hedgehog } \\
\text { pot/lesbian }\end{array}$ & $\begin{array}{l}\text { gevangenis } \\
\text { prison }\end{array}$ & $\begin{array}{l}\text { deling } \\
\text { division }\end{array}$ \\
\hline $\begin{array}{l}\text { firmadas } \\
\text { company tie }\end{array}$ & $\begin{array}{l}\text { oeverdas } \\
\text { bank badger }\end{array}$ & $\begin{array}{l}\text { graadpop } \\
\text { degree doll/pupa }\end{array}$ & $\begin{array}{l}\text { sjaal } \\
\text { scarf }\end{array}$ & $\begin{array}{l}\text { dier } \\
\text { animal }\end{array}$ \\
\hline $\begin{array}{l}\text { cabaretkas } \\
\text { cabaret cash } \\
\text { register }\end{array}$ & $\begin{array}{l}\text { kamillekas } \\
\text { camomile } \\
\text { greenhouse }\end{array}$ & $\begin{array}{l}\text { lijsterkei } \\
\text { thrush genius/boulder }\end{array}$ & $\begin{array}{l}\text { geld } \\
\text { money }\end{array}$ & $\begin{array}{l}\text { groente } \\
\text { vegetables }\end{array}$ \\
\hline $\begin{array}{l}\text { campusmunt } \\
\text { campus token }\end{array}$ & $\begin{array}{l}\text { klavermunt } \\
\text { clover mint }\end{array}$ & $\begin{array}{l}\text { kievitpalm } \\
\text { lapwing palm }\end{array}$ & $\begin{array}{l}\text { geld } \\
\text { money }\end{array}$ & $\begin{array}{l}\text { peper } \\
\text { pepper }\end{array}$ \\
\hline $\begin{array}{l}\text { avenuepand } \\
\text { avenue } \\
\text { building }\end{array}$ & $\begin{array}{l}\text { blousepand } \\
\text { blouse panel }\end{array}$ & $\begin{array}{l}\text { sjalotkruk } \\
\text { shallot } \\
\text { stool/handle/crutch }\end{array}$ & $\begin{array}{l}\text { huis } \\
\text { house }\end{array}$ & $\begin{array}{l}\text { jas } \\
\text { coat }\end{array}$ \\
\hline $\begin{array}{l}\text { zwaardstaal } \\
\text { sword steel }\end{array}$ & $\begin{array}{l}\text { tapijtstaal } \\
\text { carpet sample }\end{array}$ & $\begin{array}{l}\text { profeetroos } \\
\text { prophet rose/dandruff }\end{array}$ & $\begin{array}{l}\text { ijzer } \\
\text { iron }\end{array}$ & $\begin{array}{l}\text { monster } \\
\text { specimen }\end{array}$ \\
\hline $\begin{array}{l}\text { valiumtroep } \\
\text { valium trash }\end{array}$ & $\begin{array}{l}\text { circustroep } \\
\text { circus troupe }\end{array}$ & $\begin{array}{l}\text { segmenteend } \\
\text { segment duck/Citroën }\end{array}$ & $\begin{array}{l}\text { rotzooi } \\
\text { trash }\end{array}$ & $\begin{array}{l}\text { soldaten } \\
\text { soldiers }\end{array}$ \\
\hline $\begin{array}{l}\text { cederwortel } \\
\text { cedar root }\end{array}$ & $\begin{array}{l}\text { sinuswortel } \\
\text { sine root }\end{array}$ & $\begin{array}{l}\text { kieuwschaal } \\
\text { gill scale/bowl }\end{array}$ & $\begin{array}{l}\text { peen } \\
\text { carrot }\end{array}$ & $\begin{array}{l}\text { trekken } \\
\text { extract }\end{array}$ \\
\hline $\begin{array}{l}\text { cursusvak } \\
\text { course subject }\end{array}$ & $\begin{array}{l}\text { bagagevak } \\
\text { luggage shelf }\end{array}$ & $\begin{array}{l}\text { mantelbus } \\
\text { coat bus/tin }\end{array}$ & $\begin{array}{l}\text { beroep } \\
\text { profession }\end{array}$ & $\begin{array}{l}\text { hokje } \\
\text { box }\end{array}$ \\
\hline $\begin{array}{l}\text { portieklijst } \\
\text { porch frame }\end{array}$ & $\begin{array}{l}\text { terreurlijst } \\
\text { terror list }\end{array}$ & $\begin{array}{l}\text { medaillepool } \\
\text { medal pole }\end{array}$ & $\begin{array}{l}\text { schilderij } \\
\text { painting }\end{array}$ & $\begin{array}{l}\text { serie } \\
\text { series }\end{array}$ \\
\hline $\begin{array}{l}\text { kanonschroot } \\
\text { cannon scrap }\end{array}$ & $\begin{array}{l}\text { decorschroot } \\
\text { scenery lath }\end{array}$ & $\begin{array}{l}\text { applauskroos } \\
\text { applause } \\
\text { duckweed/core }\end{array}$ & $\begin{array}{l}\text { hoop } \\
\text { heap }\end{array}$ & $\begin{array}{l}\text { hout } \\
\text { wood }\end{array}$ \\
\hline $\begin{array}{l}\text { komplotmotief } \\
\text { conspiracy } \\
\text { motive }\end{array}$ & $\begin{array}{l}\text { mozaïekmotief } \\
\text { mosaic pattern }\end{array}$ & $\begin{array}{l}\text { spinaziekraan } \\
\text { spinach tap/crane }\end{array}$ & $\begin{array}{l}\text { reden } \\
\text { reason }\end{array}$ & $\begin{array}{l}\text { patroon } \\
\text { pattern }\end{array}$ \\
\hline $\begin{array}{l}\text { exportpier } \\
\text { export pier }\end{array}$ & $\begin{array}{l}\text { gazonpier } \\
\text { lawn worm }\end{array}$ & $\begin{array}{l}\text { tunnelknol } \\
\text { tunnel } \\
\text { turnip/horse }\end{array}$ & $\begin{array}{l}\text { zee } \\
\text { sea }\end{array}$ & $\begin{array}{l}\text { worm } \\
\text { worm }\end{array}$ \\
\hline
\end{tabular}


COOLEN, VAN JAARSVELD, AND SCHREUDER

APPENDIX (Continued)

\begin{tabular}{|c|c|c|c|c|}
\hline \multicolumn{3}{|c|}{ Prime } & \multicolumn{2}{|c|}{ Target } \\
\hline Dominant & Subordinate & Control & Dominant & Subordinate \\
\hline $\begin{array}{l}\text { oaseherder } \\
\text { oasis shepherd }\end{array}$ & $\begin{array}{l}\text { hasjherder } \\
\text { sniffer } \\
\text { sheepdog }\end{array}$ & $\begin{array}{l}\text { albumklomp } \\
\text { album clog/clod }\end{array}$ & $\begin{array}{l}\text { schaap } \\
\text { sheep }\end{array}$ & $\begin{array}{l}\text { hond } \\
\text { dog }\end{array}$ \\
\hline $\begin{array}{l}\text { coconmot } \\
\text { cocoon moth }\end{array}$ & $\begin{array}{l}\text { bajesmot } \\
\text { prison riot }\end{array}$ & $\begin{array}{l}\text { brembuis } \\
\text { broom tube/telly }\end{array}$ & $\begin{array}{l}\text { beest } \\
\text { beast }\end{array}$ & $\begin{array}{l}\text { ruzie } \\
\text { quarrel }\end{array}$ \\
\hline $\begin{array}{l}\text { enquêtekwartier } \\
\text { poll quarter }\end{array}$ & $\begin{array}{l}\text { heroïnekwartier } \\
\text { heroin quarter }\end{array}$ & $\begin{array}{l}\text { rubriekadvocaat } \\
\text { column lawyer/eggnog }\end{array}$ & $\begin{array}{l}\text { uur } \\
\text { hour }\end{array}$ & $\begin{array}{l}\text { wijk } \\
\text { district }\end{array}$ \\
\hline
\end{tabular}

(Manuscript received July 29, 1991;

revision accepted for publication August 14, 1992.) 